\title{
Un microespacio en la montaña asturiana: Presorias'
}

\author{
Margarita Fernández Mier \\ José María Fernández Hevia
}

\section{INTRODUCCIÓN}

Los estudios recientes sobre historia rural en Asturias se han enfocado hacia el análisis de los grandes dominios eclesiásticos -muy en la línea con los trabajos introducidos en España a raíz del ya clásico trabajo sobre el Monasterio de San Millán (GARCíA DE CORTÁZAR, 1969)-, y han aportado amplios conocimientos sobre una importante realidad del mundo rural medieval. Sin embargo, este desarrollo no debería hacer olvidar la posibilidad de abrir nuevas vías de estudio, tanto en lo referente al objeto de conocimiento como, sobre todo, en relación a las fuentes utilizadas, algo ya planteado en su día por algunos autores (TORRENTE, 1985), y recientemente desarrollado para el estudio de las estructuras agrarias tardomedievales asturianas (FERNÁNDEZ CONDE, 1993).

Participando de esta misma línea de investigación, el presente trabajo se centra en un espacio geográfico muy reducido, lo que facilita la explotación intensiva de un variado número de fuentes, de prospección infrecuente por el medievalista. Especial importancia ha tenido el trabajo de campo dentro de este esquema metodológico, tanto en lo que respecta al registro etnográfico como al arqueológico, si bien este último sólo ha sido utilizado en cuanto a la prospección de superficie y a la recopilación de los datos existentes sobre la zona ya publicados (AVELLO ÁLVAREZ, 1985-1986; GUTIÉRREZ GONZÁLEZ, 1982).

La combinación de todas estas fuentes -especialmente la toponimia- con las escritas clásicas, ha ofrecido un buen número de claves para la interpretación de algunas cuestiones difusas en los documentos, al tiempo que ha enriquecido los resultados finales ${ }^{2}$. El análisis documental se ha llevado hasta la actualidad, permitiendo de este modo el seguimiento de la evolución general del espacio en cuanto a titularidad y tipo de explotación económica.

La secuencia histórica del espacio estudiado, conocido desde época medieval como Presorias, se inicia en la Edad de Bronce para -sin pretender un asentamiento estable a lo largo del tiempo-, continuar con una "villa" documentada en el siglo XII, que parece estar presente hasta los siglos XIV-XVI. Con su posterior desaparición, el espacio quedará relegado a su explotación económica como zona de pasto de cierta entidad por los pueblos limítrofes, al que incluso se desplazarán rebaños de merinas procedentes de la Meseta.

I Una parte sustancial de este artículo ha sido publicada en FERNÁNDEZ MIER, M.; FERNÁNDEZ HEVIA, J.M.: "Análisis microespacial d'un despoblau baxomedieval: la "villa" de Quintaniella (Presorias, Teberga)". Cultures. Revista Asturiana de Cultura, nu 4, Academia de la Llingua Asturiana, Uviéu, 1994, pp. 83-128.

2 Una reseña sobre los principales aspectos y problemas de método en este tipo de trabajos, especialmente en lo referente a la contraposición de los diferentes tipos de fuentes: (FERNÁNDEZ HEVIA, FERNÁNDEZ MIER, 1994: pp. 493-498). 


\section{ANTECEDENTES HISTÓRICOS DE LA ZONA PREVIOS AL POBLAMIEN- TO MEDIEVAL DOCUMENTADO}

A pesar de que la primera mención documental escrita de la zona data del siglo XII, existen al menos dos indicadores de un poblamiento previo. Ambos se sitúan en lo que posteriormente será uno de los límites naturales de la "villa" medieval, en la entrada Norte de las Fouces de Estrechura -por donde hoy discurre la carretera en dirección al Puertu Ventana-: se trata de los abrigos de Freisnéu, que ocupan la cara Este del desfiladero, y la Cueva Güerta, situada en su cara Oeste.

Aunque el yacimiento de los abrigos de Freisnéu, asociado a la Edad del Hierro asturiana, carece de una cronología precisa -entre otras cuestiones, por la propia variedad estilística de sus pinturas y grabados (DE BLAS CORTINA; FERNÁNDEZ TRESGUERRES, 1989: pp. 201-203) ³-, sí puede establecerse una mayor concreción para la Cueva Güerta, un hábitat rupestre de ocupación estacional en cuya entrada se hallaron, con motivo de la ampliación de la caja de la carretera de La Plaza al Puertu Ventana, diversos restos arqueológicos:

"...una sepultura de piedras hincadas, verticalmente, en el suelo con otras horizontales hacien- do de cubierta: al levantar éstas, había un esqueleto humano completo y junto a él un jarro de bronce... Alrededor de la sepultura había muchos huesos humanos. También se dice que fue hallada una espada corta" (GUTIÉRREZ GONZÁLEZ, 1982: p. 35).

Los objetos encontrados en dicha cueva parecen indicar una ocupación altomedieval no demasiado prolongada (AVELLO ÁLVAREZ, 19851986: p. 20) ${ }^{4}$. Jarritos de bronce como el aquí hallado han sido datados en Cantabria en torno a los siglos VII y VIII (LORING, 1987: pp. I I8-126), de acuerdo también a estudios anteriores que los vinculan con el inicio de la cristianización del norte peninsular (PALOL, 1950; PALOL, 1961) 5. Si la relación de estos objetos con la expansión del cristianismo parece irrefutable, debido a su funcionalidad litúrgica -eucarística o bautismal(LORING, 1987: p. 124), es más controvertido precisar la razón última de la presencia en Asturias de algunos de estos ejemplos, debido a la variedad de situaciones ${ }^{6}$. En este caso concreto, la datación establecida -siglo VII o primeros años del VIII-, unido a la ubicación geográfica del yacimiento -en las inmediaciones de puertos que comunican con la Meseta- y a su carácter de hábitat estacional de no muy amplia permanencia, permitirían relacionar el hallazgo con una población refugiada, o de ocupación temporal (GUTIÉRREZ GONZÁLEZ, 1982: p. 35).

\footnotetext{
3 "Entre los 600 y los 800 m.s.n.m. se suceden las zonas pintadas, de manera que a medida que se asciende se pasa de los lugares bajos, donde sólo figuran representaciones esquemáticas de cabras (abrigos de Collantoria y del Pasu), hasta el sector medio, donde a los asuntos animalísticos se suman las figuras antropomórficas y diversas composiciones geométricas con ojos (los llamados "ídolos"), algunas figuras humanas tratadas con cierto detalle y varios signos...".

4 Del conjunto de los hallazgos, sólo se conserva el jarrito: "Es una pieza de bronce, repujada y acabada a torno, con asa soldada al cuerpo y remachada en el cuello. Consta de tres partes, como todos los jarritos de este mismo período artístico. El vientre es de forma globular y de él parte el cuello, cilíndrico, y de éste, a su vez, la boca de forma abocinada. Por último posee el pie que es acampanado. Le falta el fondo, al igual que todos los demás jarros hispanovisigodos. El estado es de buena conservación. Presenta, solamente, una abolladura en el cuerpo central, próxima a la unión del asa pero que no afecta a la decoración. (...) Comparado con otras piezas similares, éste presenta una decoración más rica, sobre todo en cantidad, ya que en calidad está dentro de la tónica general de ellos, si exceptuamos el asa que es, a nuestro entender, de las más bellas hasta ahora aparecidas" (AVELLO ÁLVAREZ, 1985-1986: p. 20). Estas características hacen considerar al autor que el jarrito debe ser clasificado dentro del grupo IV de la tipología establecida por el profesor Palol, perteneciente al taller leonés.

5 Frente a las tesis de Palol de atribuir los bronces hallados en Asturies a un taller leonés, que produciría desde el siglo VII hasta el $7 \mathrm{I}$ I, están las tesis que mantienen que la factura de las piezas es debida a un taller asturiano, que desarrollaría su actividad hasta fechas más tardías, atribuibles por tanto al período del reino asturiano (MANZANARES, 1959). También se ha propuesto un origen en los Campos Góticos para el taller (DIEGO SANTOS, 1979: p. 42).

6 Se ha planteado (LORING, 1987: pp. 123-124) una presencia efectiva visigoda desde el reinado de Leovigildo en Cantabria y la zona oriental asturiana, que trajo consigo la penetración del cristianismo en estas zonas, en un fenómeno que habría empezado a producirse en el siglo VI, intensificándose posteriormente. Situando geográficamente los hallazgos de estos jarros litúrgicos en Asturies, nos encontramos con dos zonas diferenciadas; así, la mayoría de ellos se sitúan en la zona oriental, núcleo inicial del reino asturiano (tres en Cangues d'Onís y uno en Pandévanes, Piloña). Solamente se han encontrado dos en zonas cercanas del interior de la montaña centro occidental asturiana, uno el aquí reseñado y otro en Llindes (Quirós), ambos en las inmediaciones de los puertos que comunican con la Meseta. De este modo, si bien los primeros podrían relacionarse con esa población que Loring constata para Cantabria ya en el siglo $\mathrm{VI}$, los dos últimos parecen estar más relacionados con una población que busca refugio en las montañas asturianas a raíz de los acontecimientos del siglo VIII.
} 
Estos testimonios materiales, vinculados al proceso de expansión del cristianismo en el Norte Peninsular, deben ponerse en relación con otros indicios surgidos del análisis del espacio, que ofrecen alguna luz acerca del carácter del asentamiento en época altomedieval: no hay que olvidar el carácter sustitutorio del cristianismo en relación a los cultos precedentes y su implantación mediante la cristianización de lugares paganos. Cabe preguntarse de este modo por el posible valor simbólico o mitológico-religioso de las pinturas rupestres de los abrigos de Freisnéu, situadas en la pared opuesta a la cueva (DE BLAS; FERNÁNDEZ TRESGUERRES, 1989: p. 202), o, ya en épocas posteriores, plantear el papel cultual de las cuevas, fuentes y ríos dentro de los pueblos asentados en la Cornisa Cantábrica: "...la religión de los primeros astures atribuía a las fuerzas naturales poderes sobrenaturales de índole impersonal; por ello nada tiene de extraño que estos seres extraordinarios de los astures primitivos se encuentren vinculados al agua, tan importante en Asturias, y al bosque, decisivo para el modo de vida de la economía de todas las épocas" (FERNÁNDEZ CONDE, 1981: pp. 99102). Precisamente, el hábitat de la Cueva Güerta conjuga esta doble potencialidad, al sumar a la cercanía de los abrigos decorados sus propias características físicas, en las que el agua tiene una enorme importancia: el río Valdesampedru desaparece y se subsume en ella a la salida del desfiladero de Estrechura, introduciéndose por los recovecos que horadan toda la peña. Existen además testimonios toponímicos y orales del carácter religioso del término, en relación a prácticas eremíticas que se habrían realizado a pocos metros de la cueva, en Cuaímbia (lat. covam), donde se encuentra La Fonte l'Ermitán ${ }^{7}$, lo que podría relacionarse con las ya reseñadas prácticas de cristianización de lugares paganos.

De todo este conjunto de referencias, parece manifestarse una cristalización en este espa- cio del modelo de cristianización del norte cantábrico, puesto que "... en Asturias, al igual que en Cantabria y en otras regiones limitrofes, el cristianismo ha procurado desplazar y transformar las prácticas y rituales paganos por el procedimiento de la sustitución. Las iglesias y santuarios cristianos fueron construidos o establecidos frecuentemente cerca de los centros de culto autóctonos: construcciones dolménicas... o santuarios paganos en cuevas, a cuya tipología corresponde, sin duda, Covadonga, antes de conver- tirse en iglesia-símbolo de la Reconquista" (FERNÁNDEZ CONDE, 1982) 8 .

\section{PRIMERAS REFERENCIAS DOCU- MENTALES: PRESORIAS EN EL SIGLO XII}

"...dabo ipsa hereditate in locum predictum, Sub Presorias, uilla prenominata in Quintanella; dabo solares, ortales, nogales, pumares, ceresales, nisares, terras domitas etiam et pro domitare, montes domitos etiam uel prauos, aquis aquarum uel sedilias molinarum, cessum, regressum quantum ad illa uilla pertinet...". (FLORIANO CUMBREÑO, 1960: pp. 170-171, doc. no 54).

Esta es la primera y más explícita mención documental -datada en el año | |62- existente sobre la "villa", referencia a partir de la cual se intentará establecer un estudio de ésta que contará con el auxilio de la información complementaria aportada por el análisis toponímico de la zona9. Los problemas de datación inherentes a la hora de trabajar con el registro toponímico, se reducen en este caso por las características peculiares del espacio, abandonado como hábitat en torno a los siglos XIV$X \mathrm{~V}$ : de esta manera, aunque con posterioridad pudiesen haberse creado nuevos topónimos o alterado algunos de los ya existentes, la estructura básica del espacio que conforma la villa -tal y como se verá más adelante-, permanecerá

\footnotetext{
7 La referencia a la fuente se obtuvo de un vecino de San Salvador, D. Raúl Alvarez Iglesias, quien atribuía el origen del topónimo a la existencia en el pasado de un ermitaño en una cueva cercana a la fuente.

8 Los ejemplos de pervivencias prerromanas asimiladas por el cristianismo, han sido ya puestos de manifiesto para espacios similares al aquí analizado (FERNÁNDEZ CONDE; SANTOS DEL VALLE, 1987: pp. 99-102).

9 El hecho de que ésta sea la primera mención de la "villa", no quiere decir, evidentemente, que se corresponda con el momento de su nacimiento: se trata únicamente de la primera evidencia de su existencia.
} 
reconocible. Consecuentemente a estas transformaciones, es evidente que la datación de los topónimos no se llevará mecánicamente hasta el siglo XII, momento en que se documenta la villa, sino que aquellos que mantienen una coherencia de pertenencia a un sistema, se datarán de un modo general en el espacio de tiempo que va entre la mencionada aparición en la documentación escrita y la desaparición del hábitat autónomo como tal, en torno a los siglos XIV-XVI. A pesar de estas precauciones -lógicas desde el punto de vista de cualquier análisis de carácter científico-, no debe sin embargo descartarse que gran parte de los topónimos que perviven en la actualidad, documentados a través del trabajo de campo, respondan a una realidad del siglo XII, tal y como por ejemplo sucede con los topónimos medievales que aparecían como límite del término.

Ya se ha visto con anterioridad la existencia de asentamientos en la zona previos a la aparición de la "villa"; junto a lo ya mencionado, existen además toda una serie de topónimos que hablan de un hábitat de tipo castreño: La Mata'l Castru, en el mismo Presorias, o El Xuegu la Bola, en el Cangueiriz -sierra que separa Presorias de la cercana aldea de La Foceicha-. La ubicación exacta del castro, ya catalogado hace años (GONZÁLEZ Y FERNANDEZ VALLES, 1976: p. 206), no es la de El Carrilón de los Moros que da el autor, sino la de Pandu -en las inmediaciones de Cangueiriz y del Xuegu la Bola-, donde hasta hace no mucho tiempo se encontraba la capilla de Nuestra Señora de Pandu.

Planteada la existencia a escasos metros de la "villa" medieval de un precedente castreño, del que se desconoce su perdurabilidad en el tiempo, debe reseñarse que la relación espacial existente entre ambos es similar a la que se da entre el resto de castros conocidos en Teberga respecto a un núcleo de hábitat de origen medieval: El Picu la Pena, en relación a Barriu; La Cogolla y La Cogollina, para con Castru; o La Garba, respecto a Berrueñu. En todos ellos, los hábitats castreños se encuentran empla- zados a escasos metros de los medievales, y siempre en una cota algo más alta. Otro tipo de cuestiones -como el mantenimiento o reocupación de los recintos castreños en la Alta Edad Media, o el momento exacto de su abandono y del surgimiento y cristalización de la nueva red de poblamiento, así como si este cambio es brusco o realizado a través de una amplia secuencia temporal-, sólo podrán tener respuesta a través de la arqueología, mediante el análisis de los despoblados medievales ${ }^{10}$.

\section{ANÁLISIS DEL MICROESPACIO}

\section{UBICACIÓN Y COMUNICACIONES}

La "villa" estaba situada en el término de Presorias (Valdesampedru, Teberga) (fig. I), lugar que aún conserva en la actualidad los topónimos y límites mencionados en la documentación medieval (FLORIANO CUMBREÑO, 1960: pp. 17017।, doc. no 54): el río San Pedru al Norte; un pequeño arroyo que desciende desde el alto de Pandu al Oeste; por último, la cresta de Pena Viguera, cerrando el término por el Sur y por el Este y separándolo de la Tierra del Privilexu (fig. 2).

El territorio, extendido entre los 750 hasta los 1.200 metros de altitud, se encuentra situado entre Freisnéu, La Foceicha, S. Salvador y Torce, pueblos todos ellos que se verán implicados en frecuentes acuerdos, arbitrios y pleitos desde el siglo XVI hasta prácticamente la actualidad por los derechos de aprovechamiento de sus pastos. En la cabecera de Valdesampedru, antes del enclave de Estrechura, el lugar da paso al pequeño valle de El Privilexu y a la vía de comunicación con la Meseta a través del Puertu Ventana, enlazando asimismo el camino que atraviesa el término de Presorias con la Calzada de La Mesa (fig. 3).

Como puede deducirse de todo lo dicho, en el emplazamiento de Presorias destacan principalmente dos características: la posibilidad de

10 Existe un estudio (FERNÁNDEZ MIER, en prensa) sobre la transformación del poblamiento altomedieval en Asturies. Para territorio castellano, existen también trabajos al respecto (MARTÍN VISO, 1995; PASTOR DÍAZ DE GARAYO, I996; ESCALONA MONGE, 1997). 
aprovechamiento de amplios espacios especialmente aptos para la ganadería, y su vinculación a importantes vías de comunicación. Respecto a la primera cuestión, debe recordarse lo ya apuntado sobre la localización del término de Presorias en la cabecera de un valle, rodeado parcialmente por corrientes de agua, y desde donde se da un fácil acceso a los pastos altos de montaña. En esta línea -y en relación con la indicada existencia de un núcleo castreño previo-, se desconoce si éste, dada su situación en altura, pudo haber servido como emplazamiento estacional vinculado a un aprovechamiento ganadero del espacio -como se ha reseñado para algunos casos similares (GONZÁLEZ Y FERNÁNDEZ VALLES, 1976: p. 184)-, o si por el contrario, se trataba de un hábitat estable. Respecto a las técnicas de explotación de estos espacios de pasto, puede aventurarse una cierta continuidad desde época protohistórica a tiempos altomedievales, sobre todo en "villas" de montaña como ésta, potencialmente más orientada hacia la ganadería que otras "villas" situadas en latitudes más bajas.

Desde el punto de vista viario, la ventajosa situación de Presorias viene dada por su relación con dos relevantes rutas que se internan en Asturias a través de los puertos de Ventana y La Mesa (fig. 3). Especialmente importante es la Vía de La Mesa, que sería ya en época romana uno de los principales ejes viarios de todo el territorio asturiano, y cuyo itinerario cuenta con una amplia bibliografía de carácter científico y un estudio pormenorizado de su trazado (URÍA RÍU, 1989; SÁNCHEZ ALBORNOZ, 1972; GARCÍA FERNÁNDEZ, 1976). Éste discurre inicialmente por el cordal que separa los actuales concejos de Teberga y Somiéu, y da lugar a toda una red secundaria de caminos en la vertiente occidental de Teberga. De entre ellos, se han señalado como más relevantes el que desde el trazado principal -y a través del Campu la Madalena y la braña de Fonfría-, va a salir a Barriu, Torce y Cuña, así como el ramal existente por la Veiga de Taxa a Santa Cristina y Marabiu, a través de la braña de Vicenturu (URÍA RíU, 1989: p. 97). La conexión en época medieval de las "villas" de la zona con la Vía de La Mesa parece haberse dado mediante los mismos caminos que aún perviven en el presente. En el caso de Presorias, este enlace se efectuaría por los actuales términos de La Foceicha, bien a través de la braña de Cuevas, bien por el camino directo de Torrestío y la braña de Las Navariegas (fig. 3).

A esta serie de caminos debe añadirse el que, procedente del puerto de Ventana, en la divisoria con León, discurría por términos de La Venta la Puerca y Parmu, para ascender finalmente a La Foceicha -evitando así la barrera natural de Estrechura, sólo transitable en determinados períodos del año-. Destaca por tanto el asentamiento de La Foceicha como núcleo en el que convergían tres caminos secundarios provenientes de León. A partir de allí, la única vía de comunicación posible con los tres valles de Teberga era el camino que, desde el alto de Pandu, descendía por Presorias hacia San Salvador. Por todo ello, resalta la ubicación estratégica de la "villa" existente en Presorias, al situarse junto al único camino de la zona en dirección a La Meseta, poco antes del cruce de caminos de La Foceicha, bien en dirección a La Mesa, bien hacia el Puertu Ventana.

\section{DELIMITACIÓN Y ESTRUCTURA INTERNA DE LA "VILLA"}

\section{Delimitación de la "villa"}

El análisis parte de la información ofrecida por el documento de I I 62 ya mencionado con anterioridad, que indica los límites del término de Presorias: "...per cunctis locis et terminis suis antiquis, per illo rio Trubia et per penna lugera et per illo Pando, et per Canguerizo, et afligit se ad illo rio de Camino" (FLORIANO CUMBREÑO, 1960: pp. 170-171, doc. no 54).

Los topónimos reseñados en el documento son aún reconocibles, y siguen definiendo el término de Presorias tal y como es conocido en el presente: de este modo, el "río Trubia" se corresponde con el actual río de Valdesampedru. "Penna Viguera" es identificable con Pena Viguera, crestón calizo que separa Valdesampedru de la Tierra del Privilexu. Otros de los límites de Presorias son "Pando" -Panduy "Canguerizo" -Cangueiriz-, situados entre La Foceicha y Presorias. El único topónimo no 
reconocible directamente es el denominado "río de Camino"; sin embargo, teniendo en cuenta la identificación del resto, no es difícil su asimilación a la pequeña corriente de agua que desciende desde Pandu al río de Valdesampedru"l.

El documento de I I 62 delimita la "villa" en toda su extensión, es decir, el término a ella adscrito, en el que se ubicaba su espacio de hábitat y en el que se desarrollaban sus actividades económicas, al menos las de carácter intensivo. El interés por delimitar el territorio debe vincularse a la ubicación de Presorias entre los términos de La Foceicha y San Salvador d'Alesga, núcleos por otro lado documentados también por estas mismas fechas 12: se trata pues de diferenciar los espacios económicos constitutivos de cada una de las "villas" colindantes, sobre todo en el momento de su consolidación como comunidades aldeanas. Hay que poner de manifiesto que los términos incluidos dentro de la delimitación documental se circunscriben únicamente al espacio de explotación particular, puesto que más allá de sus límites se extenderán aquellos de aprovechamiento comunal, en ocasiones compartidos por más de una "villa".

Además de estos topónimos, debe resaltarse la presencia actual en Presorias -en las cercanías de Pandu-, del topónimo Las Cruces, que puede estar relacionado tanto con una señal de límite entre "villas", como con su cercanía a una vía de comunicación: en efecto, y junto a límites naturales, aparecen en ocasiones cruces o mojones como delimitadores, elementos que perviven hasta la actualidad a través de la toponimia, tal y como se ha puesto de manifiesto en análisis de algunas "villas" asturianas ${ }^{13}$. Un último elemento a destacar en lo refe- rente a la definición del término de Presorias, a través del citado documento de I 162, es la expresión "...per cunctis locis terminis suis antiquis", lo que hace pensar en una temprana organización de los territorios pertenecientes a estas "villas", o al menos a ésta en concreto, al ser calificada ya entonces la delimitación como "antigua".

El espacio aparece en la documentación medieval como "Sub Presorias" ( 1 62) y "Presorias" ( I l 63) con el atributo de "locum", que parece corresponderse, más que con una categoría de poblamiento -como puede ser la "villa", con una mera localización geográfica, un término en el cual poder ubicar categorías de poblamiento. Así pues, con la denominación de "Presorias" se designaba en la Edad Media la misma realidad geográfica que en la actualidad, siendo en este ámbito ("locum") donde se ubica la "villa", denominada Quintaniella.

No debe dejar de reseñarse la significación del término Presorias. Éste hace directa relación al fenómeno de la presura "...que significa una ocupación y puede contemplar distintas situaciones, pero lo normal y general es que la ocupación signifique la adquisición de unos derechos de propiedad" (ESTEPA, 1989: p. 39), en una interpretación alejada de las concepciones de la presura como una forma de habitar lo deshabitado: "...En una sociedad donde tenía importancia la agricultura extensiva con cultivo temporal y la utilización de importantes espacios para la ganadería, era muy normal que se produjeran estos fenómenos, y sería un error interpretarlo siempre como habitar lo deshabitado" (ESTEPA, 1989: p. 39).

En efecto, habría que enmarcar esta interpretación en el proceso que tiene lugar en

\footnotetext{
II Sólo puede plantearse una pervivencia parcial del topónimo "río de Camino" en las referencias al término "río" presentes en los cercanos topónimos de La Braña'l Ríu y Reifuechas, cuya partícula inicial "rei-" es vinculable a "río".

12 La primera mención de La Foceicha se da en este mismo documento, donde aparece como límite. S. Salvador d'Alesga aparece mencionado en II 22 como "villa Elesgam" en documentación del monasterio de Curniana (FLORIANO CUMBREÑO, 1949: p. 191). Existen estudios recientes que permiten una mayor profundización en todo lo relativo a la cronología del poblamiento en el territorio de Teberga (FERNÁNDEZ SUAREZ, A., 1992).

13 Así en San Cloyo, dentro de la "villa" de Maxa, aparece como límite "...ad illam crucem", conservándose en la actualidad el topónimo de "Güerta la Cruz"; se indican también como límites "petreficxos" (FERNÁNDEZ MIER, en prensa). del mismo modo, en la parroquia de Llatores, y en los límites de las "villas" de Llatores, Ayones y Llagú, aparece el topónimo "La Cruz", en el arroyo que separa los téminos de Llatores y Llagú, muy cerca también del límite de éstos con el de Ayones (ALONSO ALONSO, I992: p. 68).
} 
época altomedieval en unos espacios caracterizados por las pervivencias de una organización territorial ligada a los asentamientos castreños, dentro de la cual se irán progresivamente estructurando los espacios de las "villas". Las transformaciones económicas que se producen -bajo la forma de cambios en la explotación del espacio y la elección de ocupaciones económicas diferentes-, generará también transformaciones de tipo territorial y social. Sin embargo, y a pesar de que este proceso de reorganización del territorio y del poblamiento en los siglos altomedievales supone grandes cambios, las pervivencias de la organización precedente no son fáciles de eliminar, continuando de hecho el "territorio" como organizador y referente espacial básico para las diversas "villas" hasta, al menos, el siglo XII (FERNÁNDEZ MIER, en prensa). Será pues dentro de este proceso de reorganización del poblamiento y de surgimiento de las aldeas -ya cristalizado en el siglo XII, a la luz de la documentación-, como hay que partir el término de Presorias y su misma etimología 14 .

\section{Estructuras de hábitat de la "villa"}

Las referencias documentales apenas aportan información sobre este punto, puesto que únicamente emplean el término genérico de "solares" para describir los elementos integrantes de hábitat de la "villa". En contraposición, el recurso a la toponimia enriquecerá enormemente el resultado final, diferenciando los espacios concretos de hábitat, cuya enumeración se realiza a continuación:

\section{Quintana / Quintaniella / El Casar / Presorias}

El "solar" -única referencia documental sobre el asunto- y la "quintana" (y por tanto su derivado Quintaniella) son términos análogos, refe- ridos no sólo al terreno que había de ocupar la casa, sino a un amplio espacio situado en torno a ella, en el que podían situarse el hórreo y los aperos, y en el que se realizaban determinadas labores relacionadas con la actividad agraria (GARCÍA FERNÁNDEZ, 1980: pp. 64-65). Una significación análoga parece tener el término "casar", que en el caso estudiado de la "villa" de Aspra (TORRENTE, 1985-1986: pp. 79-80), hace referencia a un conjunto diferenciado y delimitado dentro de ella. Ambos topónimos son indicadores de espacios de hábitat de la "villa" que hacen mención a pequeñas unidades, cuya suma da como resultado el núcleo de habitación; por ello, las menciones documentales a los "solares" se realizan en plural, haciendo clara alusión a estas diversas unidades de hábitat que componen la "villa" (ORTEGA VALCÁRCEL, 1987: pp. $32-$ 36) ${ }^{15}$.

Por último, y además de la significación reseñada en el apartado anterior -correspondiente al conjunto del término analizado-, con la denominación de Presorias se conoce también lo que hoy son unos pequeños prados colindantes con Quintana y Quintaniella. Es especialmente relevante la cercanía topográfica de los topónimos referentes al hábitat, lo que parece indicar el lugar concreto de localización del hábitat primitivo del despoblado ${ }^{16}$.

\section{Palaciu}

Topónimos también referentes al hábitat, aunque a una cierta distancia de los anteriores, son los de Palaciu y sus inmediatos de Corrada Grande y El Pibidal. El primer término puede indicar un lugar de habitación relacionado con familias detentadoras de algún tipo de poder o preeminencia dentro de la aldea, bien bajo la forma de una casa aislada o de una quintana o corral, con edificios que formasen

\footnotetext{
14 No puede olvidarse tampoco lo mencionado con anterioridad sobre la existencia de una serie de topónimos indicadores de la existencia de un asentamiento castreño en las inmediaciones de Presorias, lo que hace pensar en la relación de ambos núcleos y del sentido que puede tener la reorganización espacial señalada.

15 El autor considera al "solar" como heredero de la "domum" en cuanto que le sucede a la hora de identificar a la unidad social. El significado de "quintana" lo relaciona con la idea de partición ("quiñón", "quinta"...), parte de la heredad patrimonial. Son por tanto todos ellos términos que indican una fragmentación interna en grupos domésticos menores, en explotaciones familiares, cuyo conjunto es la "villa".

16 Existe además una tradición oral en el pueblo de Freisnéu que sitúa el despoblado en lo que actualmente es un prado que linda con los anteriormente citados: La Bronal.
} 
un conjunto más o menos compacto. Por encima del carácter concreto de su morfología, es indudable que pertenecerían a un grupo destacado dentro del campesinado. Esta característica explicaría su situación un tanto excéntrica respecto al resto del poblamiento ${ }^{17}$.

\section{La Corrada Grande / El Pibidal}

La Corrada Grande hace alusión a un espacio cerrado, aislado, mientras que El Pibidal es un semillero. A diferencia de los topónimos relacionados con una dedicación agrícola -que se verán más adelante-, ambos, inmediatos a El Palaciu, tienen un carácter marcadamente individualista.

\section{Prau La Torre / Foxeu}

Otro término similar a El Palaciu, en cuanto trasluciría una cierta preeminencia social, es el de La Torre. Este topónimo, ubicado en un conjunto de prados denominado Llamera, en las inmediaciones de los antes estudiados en referencia al hábitat (Presorias, Quintana, Quintaniella, El Casar), haría mención según tradición oral de los pueblos vecinos, a la antigua existencia de una torre, documentada ya en el siglo $\mathrm{XVI}$ a través de una sentencia arbitral sobre los pastos de la zona:

"...pues es costumbre antigua que los vezinos del lugar de La Focella, cada uno de ellos puedan apastar e comer e pazer con sus ganados en los montes e términos de Presorias y hacer parada e dormida con ellos hasta las señales siguientes: en el Caballo de Peña Utrera y de allí derecho al prado de Folo de Velasco de Tuñón, e al Canto de la Escandanada, e al cueto e otero que entra la parte de arriba de la torre de Lamera y prece o sitio que da vista a ella misma camino de Babia..." 18.

Estas torres situadas en espacios rurales, son vistas bajo el punto de vista de una estrecha relación con la economía agropecuaria (AVELLO ÁLVAREZ, 199I), aunque en este caso concreto no se descarta tampoco un carácter defensivo vinculado al camino que pasa por sus inmediaciones; de todas maneras, es clara su relación con el espacio económico del núcleo en que se encuentra ${ }^{19}$. En esta línea, en la parte baja del Prau la Torre, se encuentra el término de Foxéu (lat. fossam), cuya etimología está sin duda en relación con las propias características del terreno, explicando en parte el asentamiento de la torre, que tiene asegurada la defensa por este lado.

De todo lo dicho hasta ahora respecto al hábitat de la "villa", se manifiesta una morfología clara: un núcleo de habitación compacto (Quintana, Quintaniella...), que puede responder a los primeros siglos medievales, a partir del que muy posiblemente surgiesen en época bajomedieval un nuevo lugar de habitación (Palaciu), y se construyese la torre defensiva, fruto todo ello de unas nuevas condiciones sociales y políticas, en relación a los poderes nobiliarios.

\footnotetext{
17 El término Palaciu suele ser problemático, puesto que alude tanto a construcciones época moderna, como a topónimos de prados o montes, etc., con los problemas de datación y de análisis que esto conlleva. Suele hacer siempre referencia a un lugar de hábitat, sin que en muchas ocasiones pueda profundizarse al respecto. En (GARCÍA ARIAS, 1989: p. I I6), se plantea un interesante ejemplo -en el vecino lugar de Berrueñu-, donde existen algunas cuestiones similares a las reseñadas para Presorias: "Sopalaciu (...) la creencia popular ye que nesta zona tuvo asitiáu enantes dichu pueblu de Berrueñu fasta qu'una quema lu desfexo". Construyose, lluéu, onde agora s'alluga".

18 Archivo de la Junta Administrativa de La Foceicha, año I552. En el siglo pasado aún eran visibles sus restos, a la vez que se tenía conciencia del valor histórico del término en su conjunto (MADOZ, 1985 (reed.): p.28, voz "Alesga"): "En el pueblo de Fresnedo y sitio de La-Torre se ven los restos de un torrejón o cast.(illo) en cuyas cercanías se cree existía un conv. de templarios, que desapareció por hundimiento del terreno, en el cual se encuentran hoy trozos de piedra labrada y algunos de tejas". La explicación de "hundimiento del terreno" en Presorias se recoge también en la tradición popular de Freisneu como motivo de la fundación del pueblo, en la ladera contraria. Una cuestión similar se ha visto ya para el vecino caso de Berrueñu (vid. notas no I7 y |8). La prospección de campo no ha facilitado ningún testigo material visible al respecto, aunque la existencia de un pequeño promontorio en la parte superior del prado nos indica una posible ubicación de la construcción fortificada. Lo más significativo del lugar es su situación estratégica respecto a las vías de comunicación mencionadas con anterioridad, su comunicación visual directa con el Castillo de Alesga y con gran parte del conjunto del valle de Valdesampedru. (ALVARGONZÁLEZ TREMOLS; CASERO TORRE, 1992: p. 228).
}

19 La existencia, dentro del término de Quintana, del espacio denominado La Capiella, en las cercanías del Prau la Torre, hace pensar en la posibilidad de una pequeña construcción religiosa ligada a la torre. 
San Vicente / Pozu'l Ministeriu

Cerrando la relación de elementos de hábitat que configuran la aldea, se encuentra el "monasterio de San Vicente", del que existe constancia documental -año | I22- y topomímica -actuales prados de San Vicente y del Pozu'l Ministeriu ${ }^{20}-$ :

"...et in Tebrega in valle Sancti lohannis uarcenam et illud castellum Sancti Petri cum omni sua mandatione et cum uillis et monasteriis praenominatis Monasterium Sancti Uincentii de Presorias, monasterium Sancti lusti de Paramo cum suis deganeis, monasterium Sancte Eulalie de Torze et Sancti Christofori de Cunia et uillam Elesgam..."(FLORIANO CUMBREÑO, 1949: pg. 191) 21.

Un problema importante es delimitar el carácter de estos centros religiosos, aparecidos en la documentación indistintamente como "ecclesiae" y como "monasterios"; aunque no es fácil conocer el sentido originario de estos pequeños núcleos en la Alta Edad Media, no parece que todos ellos deban ser considerados como monasterios: "...no es posible apreciar unas nítidas diferencias entre iglesias y monasterios, pues lo que nos encontramos son pequeñas iglesias de comunidades rurales, con cuyos topónimos se identifican, servidas por reducidos grupos monásticos" (LORING, 1987: p. 352). Parece de este modo que estos "monasterios" no son más que lugares de culto que probablemente surgen ligados a una comunidad y por iniciativa de la misma, de ahí que a menudo se identifiquen con el nombre de la villa (en este caso con el del término genérico -Presorias-) y que posteriormente, al igual que ocurre con las propias "villas", irán cayendo bajo el dominio de la nobleza que se gesta en los siglos X-XII, de modo que cuando sur- gen en la documentación aparecen siempre en manos de ciertas familias aristocráticas, en un destino paralelo al proceso de diferenciación social dentro de la comunidad aldeana. Algunos de estos monasterios estarán sin duda fundados por estas mismas familias que por alguna razón deciden constituirse en una comunidad monástica dando lugar a las "iglesias propias". No hay que olvidar a este respecto la importancia económica que tenían estas iglesias, de lo que son testimonio los intentos de monasterios y Mitra ovetense para conseguir el control sobre ellas, ya que eran "...centros productores de rentas, bien sean derivadas de la explotación de su patrimonio, bien del ejercicio de sus funciones parroquiales, y además actúan como patronos espirituales y temporales, lo que favorece el continuo incremento de sus patrimonios y el que en su entorno se anuden relaciones de dependencia, rentas y hombres de los que en última instancia se benefician sus patrones laicos" (LORING, 1987: p. 357).

En síntesis, y respecto a todo lo expuesto en relación al hábitat de la "villa", se conoce con certeza la ubicación del lugar de habitación y del centro religioso a él asociado. Se sabe asimismo de la existencia de un núcleo de habitación, posiblemente indicativo de un cierto poder dentro de la comunidad, así como de una torre que entraría en esta misma línea de análisis, correspondiéndose sin duda estas dos últimas construcciones a un momento posterior al que se nos describe en el documento de 1162 .

\section{El espacio agrario de la "villa"}

El análisis toponímico del espacio (fig. 4) será, al igual que ocurriera con el hábitat, una de las bases para el estudio de las cuestiones relacio-

\footnotetext{
20 Presente en la actualidad, ya se recoge en el siglo pasado la tradición oral de la existencia del monasterio, cuando ya no quedaba de él sino un recuerdo cargado de connotaciones legendarias (convento de templarios, desaparecido por un hundimiento del terreno) (MADOZ, 1985 (reed), voz "Alesga"). En las inmediaciones de S. Vicente, habrían asimismo aparecido tumbas de lajas con motivo de trabajos agrícolas por los vecinos de Freisneu (AVELLO ÁLVAREZ, 1985-1986).

21 Esta versión del documento presenta algunas incorrecciones geográficas, al localizar los cuatro monasterios, junto a la "villa" de Alesga y el castillo de S. Pedru en Valdesantibanes, cuando sólo Bárzana está en dicho valle. En otra versión diferente del mismo documento (FERNÁNDEZ CONDE, 1972, pp. 178-182), las referencias geográficas especificadas en el documento son más exactas, localizando las diversas heredades en sus valles correspondientes, y denominando a estos centros religiosos "ecclesiae" y no "monasterios": "...In Tebrega in valle de Sancto lohanne Varzena, in Carzana Texera, quantum ibi habemus tam de parte parentum quam etiam de nostra adquisitione; in valle Sancti Petri ecclesiam Sancte Eulalie de Torze, Sanctum Christoforum de Cunia, ecclesiam Sancte Vincentii, ecclesiam Sancti Justi de Praramo cum omnibus adjuntionibus suis, Elesga, castellum Sancti Petri cum omnibus villis et hereditatibus suis...".
} 
nadas con la actividad económica que desarrollaban los pobladores del asentamiento.

No obstante, el punto de partida para el estudio del espacio agrario de la "villa" será el ya citado en varias ocasiones documento del año 1 162, ya que ofrece una idea aproximada de su estructura. Destaca en él la mención explícita de los huertos, no incluidos dentro del espacio ocupado por el "solar" -son enumerados por separado, como cosas distintas-, a diferencia de lo que ocurre normalmente dentro de la documentación medieval. A su vez, es especialmente reseñable la importancia que los frutales debieron tener dentro de la economía de la "villa", a juzgar por la detallada enumeración de ellos: "...nogales, pumares, ceresales, nisares..."; su localización física es desconocida, aunque parece significativo que se mencionen a continuación de los huertos y con anterioridad a los espacios cerealísticos; esto induce a pensar en lugares especialmente acondicionados para ellos -sobre todo en el caso del manzano- y muy cercanos al espacio del hábitat, al igual que ocurre con los huertos, en una localización constatada en otras zonas del Cantábrico durante la Edad Media, como es el caso de la Liébana: "Los frutales se sitúan preferentemente en las proximidades del solar o de la casa, e incluso aparecen en huertos o "ferrenes", buscando en otros casos la proximidad de ríos o arroyos; no obstante, pensamos que una característica de los frutales, a la luz de la documentación, es su gran ubicuidad, pues en otras ocasiones los encontramos al lado de tierras, viñas o prados, aunque quizá sería posible una evolución que los va incluyendo en los huertos o alrededores de la casa" (GARCíA SAHAGÚN, J., 1986: pp. 35-36). El hecho de que aquí se mencionen las distintas especies de forma individualizada, pone de manifiesto la gran importancia que éstas debían tener para la economía campesina. De todas las referidas en la documentación, es destacable la presencia de manzanos, -en relación con el papel tradicional de la sidra, equivalente al vino de otras latitudes-, que se traduce toponímicamente en la pervivencia del topónimo La Carueza, vinculable con la localización de este frutal en un lugar determinado dentro del espacio de la "villa" -y en concreto en las inmediaciones del río-, en situación marginal respecto al hábitat (GARCÍA ARIAS, 1977: p. 145).

Tras la enumeración de frutales, en el documento se mencionan las "terras domitas etiam pro dominare", siendo esta la única información existente sobre los espacios de dedicación cerealista, en lo que podría ser una alusión a la dicotomía de tierras puestas en explotación frente a otras yermas, o a tierras cultivadas en un momento determinado en oposición a otras que pudieran estar sin cultivo ${ }^{22}$. Frente a la parquedad de datos de la documentación, el registro toponímico habla de la dedicación cerealista especializada de determinados terrenos de la "villa", y de su localización concreta, a través de la existencia de los topónimos de La Escandanada, La Bronal y La Ordaliega. Ninguno de ellos aparece documentado en época medieval, aunque los dos primeros sí lo están ya en el siglo $\mathrm{XVI}$, lo que hace pensar en su origen medieval:

"...hasta las señales siguientes: en el Caballo de Peña Utrera y de allí derecho al prado de Folo de Velasco de Tuñón e al Canto de la Escandanada, e al Cueto e Otero que entra la parte de arriba de la Torre de Lamera y prece o sitio que da vista a ella misma camino de Babia, e que más allende de todo ello, que sea a la fuente de la Goronal para arriba..." 23.

\section{La Escandanada}

Hace referencia a un espacio agrícola dedicado al cultivo de la escanda, uno de los cerea-

\footnotetext{
22 Así, la expresión "terras domitas etiam pro dominare" quizás aluda a las características que tenían las erías (cortinales, en Teberga) en época medieval: éstas, aún siendo espacios acotados, no estaban ni mucho menos roturadas en su totalidad, de tal modo que existían en su interior espacios dedicados a roza o arbolado, siendo por lo tanto posible que la citada formula medieval se refiera a la contraposición de las zonas de las erías puestas en explotación y aquellas que aún no han sido roturadas. Para profundizar en el carácter de las erías en época medieval, existe un amplio y reciente trabajo (FERNÁNDEZ CONDE, 1993).

23 Archivo de la Junta Administrativa de La Foceicha. Año 1552. Se trata de una copia mecanografiada con abundantes errores de transcripción, fruto de la dificultosa lectura de un documento original, no conservado. Se ha procedido a la identificación del topónimo "Goronal" por el actual de Bronal, pudiendo responder las diferencias a estas cuestiones.
} 
les más cosechados en Asturias por su resistencia al frío y su particular adaptación al medio, de la que existen numerosas constataciones ya desde época medieval.

\section{La Bronal}

Mayores problemas plantea el topónimo de La Bronal, al asociarse éste en primera instancia con la borona -entendida como pan de maízlo que imposibilitaría el origen medieval del término. Sin embargo, el hecho de que el topónimo aparezca documentado ya en el siglo XVI, con anterioridad a la introducción del maíz en tierras asturianas, hace pensar que esta asociación no es correcta: en efecto, tanto en Cantabria como en Galicia hay referencias medievales al respecto, dándose una identificación entre los términos borona y mijo hasta la llegada y desarrollo del maíz ${ }^{24}$. La rápida aceptación y difusión de este cereal de primavera, cuyas primeras cosechas en Asturies se estiman producidas alrededor de 1605 (GARCÍA FERNÁNDEZ, 1980: p. 95), traería así el que en ocasiones reciba denominaciones originadas en los cereales que se cultivaban con mayor asiduidad y a los que terminó suplantando casi totalmente, llegando en el caso gallego a provocar el cambio del nombre del mijo. Todas estas referencias, así como la ya mencionada constancia de la existencia del topónimo en 1552, cuando las primeras cosechas de maíz no se obtendrán hasta el siglo siguiente, permiten afirmar que la etimología del término La Bronal hace referencia al mijo o al panizo, como ocurría en los casos anteriormente citados.

\section{La Ordaliega}

La existencia del término La Ordaliega, un tanto marginal respecto al resto, no hace sino complementar las noticias anteriores de espacios específicamente dedicados al cereal den- tro de la "villa", en este caso dedicados al cultivo de la cebada (lat. hordeum).

De este modo, pueden conocerse los cultivos que se realizaban en esta "villa" mediante la fosilización de, fundamentalmente, dos topónimos que hacen referencia a esta cuestión. Poco más puede saberse sobre el funcionamiento de estos espacios. Solamente la presencia del sufijo -al que aparece en La Bronal -con sus connotaciones colectivas-, puede dar pie a plantear que el espacio se refiere a un conjunto de tierras, que aún estando dedicadas a un mismo cultivo, estaban, de alguna manera, diferenciadas en su estructura interna. No puede saberse por tanto si existía una rotación de cultivos entre los dos espacios, o si los cereales eran todos los años trabajados en un mismo sitio, lo que traería consigo la necesidad de la práctica del barbecho para permitir que el terreno descansase y se regenerase. Por otro lado, la existencia de un tiempo en que la tierra no está ocupada por el cereal -de agosto a noviembre en caso de la escanda y del verano hasta abril en el caso del mijo-, daría lugar a un aprovechamiento temporal de aquella como espacio de pasto. Esto conduce a otras dos cuestiones ya mencionadas: la referencia documental de las "terras domitas etiam pro dominare", y la estructuración del terrazgo en erías o cortinales que ha llegado hasta nuestros días, en referencia a un espacio dedicado a un mismo cultivo, en las cercanías del núcleo de hábitat (ÁLVAREZ MENÉNDEZ ET ALII, 1990: pp. 148-152). No obstante, de la suma de las escasas referencias documentales conservadas sobre el espacio dedicado a tierras cultivables, así como de la pequeña extensión territorial a que hacen referencia los topónimos mencionados y de las condiciones geográficas en que se asentaba la "villa", puede suponerse que fuese mayor el peso de las actividades ganaderas que el de las agrícolas.

\footnotetext{
24 "Pan de maíz. En Pas suena "brona". Hasta el siglo XVII, en que se extendió en Cantabria el cultivo de esta gramínea, recibía tal nombre el panizo o mijo de verano, de quien lo tomó el maíz, al sustituir su cultivo..." (VV.AA, 1985). Idem., voz "Mijo", en Cantabria el término "boronal" se refiere a un lugar sembrado de borona (mijo). Este cereal de primavera, bajo el nombre de "borona" en diversas comarcas cántabras, fue cosechado en combinación con la escanda, constatándose ya su producción en el Libro de las Behetrías. En el caso gallego, la suplantación de ambos cultivos afectará incluso al propio nombre que recibirá el maíz, conocido allí como "millo": Voz "Millo" (V.AA., 1974): "...El millo miudo es el nombre con el que se designa en Galicia el Panicum miliaceum L., antes conocido como millo, pero a raíz de la introducción del maíz, vegetal que le sustituyó, y para distinguir uno del otro, se modificaron los nombres, quedando el del millo miudo, millo dos páxaros y painzo para el Panicum milliaceum y el de millo para el maíz (Zea maris)".
} 


\section{El Bouzón / La Fonte las Bouzas}

Otros dos topónimos de gran importancia para la organización del espacio cerealícola son Bouzón y Las Bouzas (La Fonte Las Bouzas), ambos provenientes del mismo étimo -Bouza-, que hace referencia a un terreno desbrozado para su puesta en explotación, una roza, lo que es indicativo de un momento de expansión del espacio cultivado o de pasto, motivado sin duda por un aumento de población que exige mayores recursos. No puede saberse la fecha de esta roturación, aunque los topónimos son, al igual que el resto de los citados, adscribibles a época medieval. En este caso, dado que Bouzón es el término anexo a La Bronal, indica una expansión de ese espacio de cereal en un momento en que se precisan mayores recursos cerealícolas.

\section{Espacios de explotación ganadera y forestal de la "villa"}

La vertiente ganadera de la explotación de la "villa" es también mencionada en la documentación medieval, al aparecer en ella lugares de pasto, prados que posiblemente estuviesen localizados en las inmediaciones de los espacios cerealícolas, como pudo quedar atestiguado por la toponimia con nombres como La Veiga Presorias, Pradichón o La Braña'l Ríu, si bien la datación de estos topónimos resulta harto problemática, al continuar el término de Presorias tras su despoblamiento convertido en un espacio ganadero hasta la actualidad ${ }^{25}$. La referencia a los "montes domitos" en oposición a otros "indómitos" haría quizás alusión a aquellos en los que se llevan a cabo más trabajos que la simple recolección, jugando un papel más activo la mano del hombre.

Cercano al posible núcleo de hábitat, al espacio cerealista y a S. Vicente, aunque en una zona sombría y poco apta para cualquier otra actividad que no fuese la conservación del monte, se encuentra el término de Monte Refuechas, que testimoniaría un espacio de monte dentro de los términos de la propia villa, en contraposición a los derechos a montes comunales que ésta podría tener fuera de sus propios términos, bien sola o en unión a otras "villas".

Para finalizar el análisis del espacio agrario, y a modo de síntesis, existe en el microespacio analizado una "villa" con dos claros núcleos de hábitat, habiéndose estructurado el terrazgo en torno al primero (Quintaniella, Quintana, El Casar), y siendo probablemente el segundo núcleo de hábitat de origen bajomedieval. El cereal parece haber ocupado un espacio poco significativo, mientras que los frutales habrían adquirido gran relevancia, dentro de un medio potencialmente muy apto para la ganadería: el emplazamiento geográfico de la "villa" y su vecindad a unos espacios de pasto privilegiados como las brañas del cordal de La Mesa, -espacios no fácilmente detectables en la documentación medieval aunque sin duda escondidos bajo las fórmulas genéricas "cessum et regressum", "entradas et salidas", "monte e valle", en las que se ceden los derechos que se tienen por habitar en el núcleo a que están asociados (ÁLVAREZ MENÉNDEZ ET ALII, 1990: pp. 167, ss)-, hacen muy posible su explotación de cara a la ganadería.

Un último elemento a destacar es la aparición de molinos en la documentación "aquis aquarum uel sedilias molinarum", conservándose cercano al río S. Pedru el topónimo So'l Molín, en cuyos términos existía hasta hace algunos años un molino, posible heredero de un antecedente medieval.

\section{LOS PROPIETARIOS DE LA "VILLA"}

Las escasas noticias documentales señalan como copropietarias a dos familias de gran relevancia en la vida política del siglo XII asturiano: así, si el monasterio de San Vicente aparece en 1122 formando parte del patrimonio del cenobio de Curniana anexionado por los Condes Suero y Enderquina al monasterio de 25 Así pues, si bien estos topónimos pueden tener un origen medieval, la continuidad de las prácticas ganaderas hace que también
hayan podido haber cristalizado en Edad Moderna. 
Cluny (FLORIANO CUMBREÑO, 1953: pp. II, ss.), la "villa" de Quintaniella aparece en la documentación con, al menos, dos poseedores: en primer lugar, Vermudo Frolaz, quien tras haberla obtenido previamente por cambio de otra, la dona en 1 I 62 a Balmonte. Dos años más tarde, en 1 164, serán los Condes Petrus Adefonsi y María Frolaz quienes donen al monasterio de Balmonte las "hereditates" de "Font Trasmiro", "Quintaniela" y "Camino", en alusión quizás a esta misma villa (FLORIANO CUMBREÑO, 1963: p. 194) ${ }^{26}$; se trataría pues de un proceso de donaciones de distintas porciones de unas "villas", fragmentadas por las continuas divisiones hereditarias a que estaban sometidas unas propiedades ligadas por mitades, tercios, o cuartas partes, a los diversos herederos.

Junto a estas grandes familias, será el mismo rey Fernando II quien ostente derechos sobre los términos de Presorias: en 1163 el monarca donará al monasterio de Balmonte la heredad de Parmu junto a los mencionados derechos sobre Presorias, de naturaleza desconocida, pero que indican una vez más la fragmentación de la propiedad existente en la "villa". El resultado final será el paso del espacio a manos de los monasterios de Balmonte y Curniana, en un proceso ilustrativo de la tendencia general vigente durante todo el siglo XII de enriquecimiento de los monasterios gracias a las donaciones nobiliarias y reales ${ }^{27}$.

\section{PRESORIAS EN ÉPOCA MODERNA}

Desde el siglo XII hasta el XVI, cuando aparece como un lugar eminentemente ganadero, no se ha tenido más constancia documental del espacio analizado. Un pleito de 1595, establecido por una casa y sus estancias anexas en el término de Presorias, indica que el despoblamiento de éste -del que se desconocen las fechas y causas concretas-, podría no haberse producido del todo ${ }^{28}$. El mencionado despoblamiento, podría estar en relación con los procesos de reorganización del poblamiento que tuvieron lugar en los siglos bajomedievales, en los que se abandonan pueblos y se producen desplazamientos de población en búsqueda de una mejora de sus condiciones, produciéndose la aparición de las aldeas yermas. En esta línea, habría que recordar la tradición oral del pueblo de Freisnéu según la cual su ubicación originaria se situaba en el término de Presorias, habiéndose producido el traslado a su actual situación a causa de un corrimiento de tierras ${ }^{29}$.

Lo cierto es que cualquiera que haya sido la fecha final, ya desde mediados del siglo XVI y con anterioridad al mencionado pleito, el espacio de Presorias o sus divisiones internas como la "Quintaniella" de la documentación medieval- pierden su autonomía, pasando a ser el conjunto un término explotado en exclusividad por las aldeas limítrofes: en 155 I, I580 y $1610^{30}$, se establecen sentencias arbitrales en las que los pueblos de Freisnéu, S. Salvador y La Foceicha delimitan las señas hasta las que pueden llegar cada uno de ellos con sus ganados, en un intento por parte de las tres aldeas de hacerse con el control de un importante espacio de pasto que hasta entonces había pertenecido a un núcleo habitado y que al desplazarse o abandonarse, trae consigo la necesidad de una reorganización en cuanto a derechos y titularidad para su aprovechamiento económico. Será Freisnéu el pueblo que parece obtener mayores derechos sobre la zona, en una cuestión quizás relacionada con lo mantenido por la tradición -surgimiento del pueblo tras el abandono del antiguo hábitat-, o

\footnotetext{
26 El linaje de Petrus Adefonsi, refundador del monasterio de Balmonte está recogido por Floriano Cumbreño (1950: 303, ss). Las afinidades cronológicas y toponímicas (reducción de los topónimos "Quintaniela", "Camino" y "Font Trasmiro") han Ilevado a García Arias (1988: pp. I09-I I0) a identificar, con algunos reparos, la mencionada villa del documento de I I64 con la ubicada en el término de Presorias, documentada ya en 1162.

27 Más información sobre la actitud de la realeza con las instituciones eclesiásticas en cuestión de donaciones, en Fernández Conde (1978: pp. 230-231).

28 I.D.E.A., Archivo de Valdecarzana, caja 3, leg. 21.

29 Vid. notas no 16 a 18. Sobre la crisis bajomedieval y el surgimiento de los despoblados ha trabajado E. García (I990)

30 Archivo de las Juntas Administrativas de Parmu y La Foceicha.
} 
quizás por una mayor cercanía en caso de una coexistencia anterior. De lo que no existe ninguna duda, es de la importancia que este lugar tuvo como espacio de pasto, ya que incluso sus "yerbas" eran arrendadas a los pastores de merinas que venían del Sur de la Cordillera Cantábrica, lo que originaba un importante cúmulo de rentas ${ }^{3 !}$.

\section{BIBLIOGRAFÍA}

ALONSO ALONSO, Gabino Arcadio (1992, inédito): Santu Tomás de Llatores. Una parroquia del alfoz ovetense durante la Edad Media. Estructura del poblamiento y morfología agraria, Oviedo.

ÁLVAREZ MENÉNDEZ, Benjamín; FERNÁNDEZ HEVIA, José María; FERNÁNDEZ MIER, Margarita; LÓPEZ CALVO, María José (1990): "Espacio y propiedad en un territorio de montaña: La Tierra del Privilexu (Teberga)", Boletín del Instituto de Estudios Asturianos. No 133, Oviedo, pp. 148-152.

ALVARGONZÁLEZ TREMOLS, Eva; CASERO TORRE, Aurora (1992): "Fortificaciones medievales de Teverga", III Congreso de Arqueología Medieval Española. Oviedo, pp. 228, ss.

AVELLO ÁLVAREZ, J. Luis (| 985-1986): "El jarro hispano visigodo de Alesga y algunas consideraciones generales sobre estos tipos de objetos litúrgicos", Asturiensia Medievalia, 5. Oviedo.

AVELLO ÁLVAREZ, J. Luis (|99|): Las torres señoriales de la Baja Edad Media Asturiana. León.

DE BLAS CORTINA, Miguel Angel; FERNÁNDEZ TRESGUERRES, Juan (1989): Historia primitiva de Asturias, Gijón.

CUARTAS RIVERO, Margarita (1983): Oviedo y el principado de Asturias a fines de la Edad Media, Oviedo.

DIEGO SANTOS, Francisco (1979). "De la Asturias sueva y visigoda", Asturiensia Medievalia, 3. Oviedo.

ESCALONA MONGE, J (1997): "Acerca de la territorialidad en la Castilla altomedieval: tres casos significativos". Historia social, Pensamiento Historiográfico y Edad Media: homenaje al profesor Abilio Barbero. Edit. M. I. Loring García. Madrid. pp. 217-244.

ESTEPA, Carlos (1986): El nacimiento de León y Castilla (sgs. VIII-IX). Historia de Castilla y León, 3.
FERNÁNDEZ CONDE, F. Javier (1972): La Iglesia de Asturias en la Alta Edad Media, Oviedo.

FERNÁNDEZ CONDE, F. Javier (1978): "El medievo asturiano (siglos X-XIII)", Historia de Asturias, vol. IV, Salinas.

FERNÁNDEZ CONDE, F. Javier (1982): "La Iglesia en el reino astur-leonés", en Historia de la Iglesia en España, vol II. I, Madrid .

FERNÁNDEZ CONDE, F. Javier (198I): "La religiosidad popular asturiana", Enciclopedia Temática Asturiana, vol 8., Gijón.

FERNÁNDEZ CONDE, F. Javier (1993): El señorío del cabildo ovetense. Estructuras agrarias de Asturias en el tardo medievo. Oviedo.

FERNÁNDEZ CONDE, F. Javier; SANTOS DEL VALLE, M. Carmen (1987): "Toponimia y tradiciones del Monsacro", Lletres Asturianes, n. 23, Uviéu, pp. 99-102.

FERNÁNDEZ HEVIA, José María; FERNÁNDEZ MIER, Margarita (1994): "Notas metodológicas para el análisis microespacial de un despoblado medieval de montaña", IV Congreso de Arqueología Medieval Española: sociedades en transición: Actas. vol II. Alicante/Alacant, pp. 493-499.

FERNÁNDEZ MIER, Margarita; FERNÁNDEZ HEVIA, José María: "Análisis microespacial d'un despoblau baxomedieval: la "villa" de Quintaniella (Presorias, Teberga)". Cultures. Revista Asturiana de Cultura, nu 4, Academia de la Llingua Asturiana, Uviéu, 1994, pp. 83-128.

FERNÁNDEZ MIER, Margarita (en prensa): "Génesis del territorio en la Edad Media: Arqueología del paisaje y evolución histórica en la montaña asturiana", Asturiensia Medievalia, Oviedo.

FERNÁNDEZ SUÁREZ, A. (1992): Teverga, un concejo de la montaña asturiana en la Edad Media, Oviedo.

FLORIANO CUMBREÑO, A.C. (1949): Colección de fuentes para la Historia de Asturias. El Monasterio de Cornellana. Oviedo.

FLORIANO CUMBREÑO, A.C. (1950): El libro registro de Corias, 2 vols. Oviedo.

FLORIANO CUMBREÑO, A.C. (1960): Colección diplomatica del Monasterio de Belmonte, Oviedo.

GARCÍA ARIAS, X. LL. (1977): "De toponimia tebergana (III). Fitotoponimia", Boletín del Instituto de Estudios Asturianos, $\mathrm{n}^{\circ}$ 92. Oviedo.

GARCÍA ARIAS, X. LL. (1988): "De toponimia tebergana $(X)$. Hidrotoponimia", Lletres Asturianes, no 30, Uviéu.

3I En un documento del Registro General del Sello, con data de I550 (CUARTAS RIVERO, I983), los vecinos de Parmu se quejan de que, estando en pacífica posesión de pastar con sus ganados en los términos de Presorias y otros, éstos eran entregados en arrendamiento a los ovejeros y pastores extranjeros. La forma de explotación de este espacio como lugar de pasto en época moderna, en Alvarez Menéndez et alii (1990; pp. 157-159). 
GARCÍA ARIAS, X. LL. (1989): "De Toponimia Tebergana (XI): La vivienda humana", Lletres Asturianes, no 33, Uviéu.

GARCÍA ARIAS, X. LL. (1989): "De toponimia tebergana (III): Les depresiones, cavidaes y lo llano"; Lletres Asturianes, no 34, Uviéu.

GARCÍA DE CORTÁZAR, J.A. (1969): El dominio del monasterio de San Millán de la Cogolla (siglos X al XIII). Introducción a la historia rural de Castilla altomedieval, Salamanca.

GARCÍA FERNÁNDEZ, Jesús (1980): Sociedad y organización tradicional del espacio en Asturias, Gijón.

GARCÍA FERNÁNDEZ, José Luis (1976): El Camino Real del Puerto de La Mesa, Oviedo.

GARCÍA GARCÍA, Élida (1990): "La crisis bajomedieval en Asturias", Historia de Asturias, II. La época medieval. Ed. La Nueva España. Oviedo.

GARCÍA SAHAGÚN, J. (1986): La organización del espacio agrario en la Liébana durante la Edad Media, Santander.

GONZÁLEZ Y FERNÁNDEZ VALLES, José Manuel (1976): Asturias protohistórica. Historia de Asturias, vol. II. Salinas.

GUTIÉRREZ GONZÁLEZ, José Avelino (1982): "Hábitats rupestres altomedievales en la Meseta Norte y Cordillera Cantábrica", Estudios Humanísticos, 4, León.

LORING, M. I. (1987): Cantabria en la Alta Edad Media: organización eclesiástica y relaciones sociales, Madrid.

MADOZ, Pascual (1985): Diccionario Geográfico-Estadístico-Histórico de España (1945-1850). Asturias (reedición, facsímil). Valladolid..

\section{RESUMEN}

El presente trabajo es el análisis microespacial de un despoblado medieval situado en la montaña asturiana. La utilización del mayor número posible de fuentes, de carácter diverso -documentales, toponímicas, trabajo de campo-, ha permitido delimitar el término de la antigua aldea, así como conocer su estructuración interna -hábitat, espacios de cultivo, características del aprovechamiento agrícola y ganadero, etc.-. El análisis se completa con una visión de los antecedentes inmediatos de la villa medieval, así como de la evolucion posterior del espacio tras su abandono como núcleo habitado y su conversión en espacio de pasto para el ganado de las aldeas vecinas.
MANZANARES, Joaquín (1959): "Bronces prerrománicos de tipo visigodo en Asturias: jarros y patenas. Boletín de la Comisión Provincial de Monumentos, n. 2. Oviedo.

MARTÍN VISO, I. (1995): "Poblamiento y sociedad en la transición al feudalismo en Castilla: castros y aldeas en la Lora burgalesa". Studia Historica. Hn Medieval, 13.

ORTEGA VALCÁRCEL, Julio (1987): La Cantabria rural: sobre la Montaña, Santander.

PALOL, P.(1950): Bronces hispano-visigodos de origen mediterráneo. Jarritos y patenas litúrgicas. Barcelona.

PALOL, P. (|96|): "Bronces litúrgicos hispanovisigodos y sus perduraciones", en Homenaje al profesor $C$. de Mergelina, Murcia.

PASTOR DÍAZ DE GARAYO (1996): Castilla en el tránsito de la antigüedad al feudalismo: poblamiento, poder político y estructura social del Arlanza al Duero (sgs. VII-XI). Junta de Castilla y León. Consejería de Educación y Cultura.

SÁNCHEZ ALBORNOZ, Claudio (1972): "Una vía romana en Asturias. La Vía de la Mesa y Lutos". Orígenes de la Nación Española. Estudios críticos sobre la historia del Reino de Asturias. Oviedo.

TORRENTE FERNÁNDEZ, Isabel (1985-1986): "Términos agrarios en el medievo asturiano (siglos X-XII)", Asturiensia Medievalia 5, Oviedo.

URÍA RÍU, Juan (1989): "Las campañas de Hixem I contra Asturias (794-795) y su probable geografía". Estudios de historia de Asturias, Gijón.

W.AA. (1985): Gran Enciclopedia de Cantabria, t. II. Santander.

V.AA (1974): Gran Enciclopedia Gallega, t. XXI, Gijón.

\section{ABSTRACT}

This work is an micro-spatial analysis of a medieval uninhabited place located in Asturias highlands. The use of various kind of sources -documents, study of place-names, fieldwork- made possible to define the old village's limits and to know its internal structure -habitat, fields, and notes about agricultural uses-.

This analysis is completed with a vision of previous establishments to that medieval villa; also, with a study of the village and surrounds evolution after the depopulation, when it was transformed in pastures for the nears villages profit. 


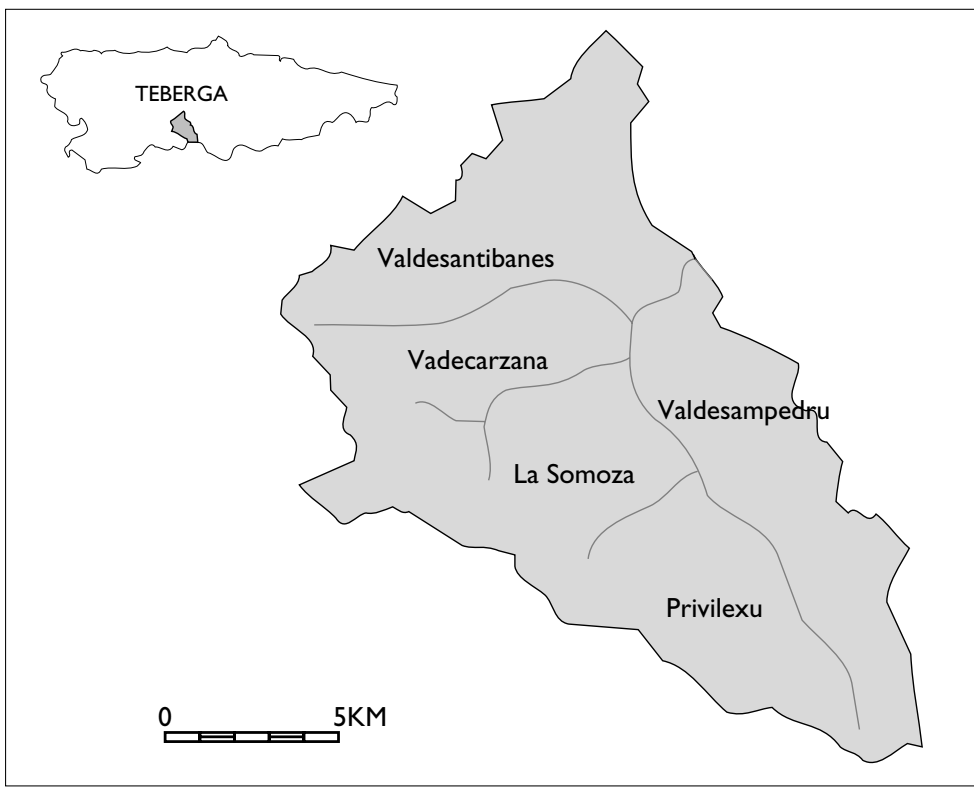

Fig. I. Localización del Concejo de Teberga y sus valles

Fig. 2. Localización de Presorias en Valdesampedru

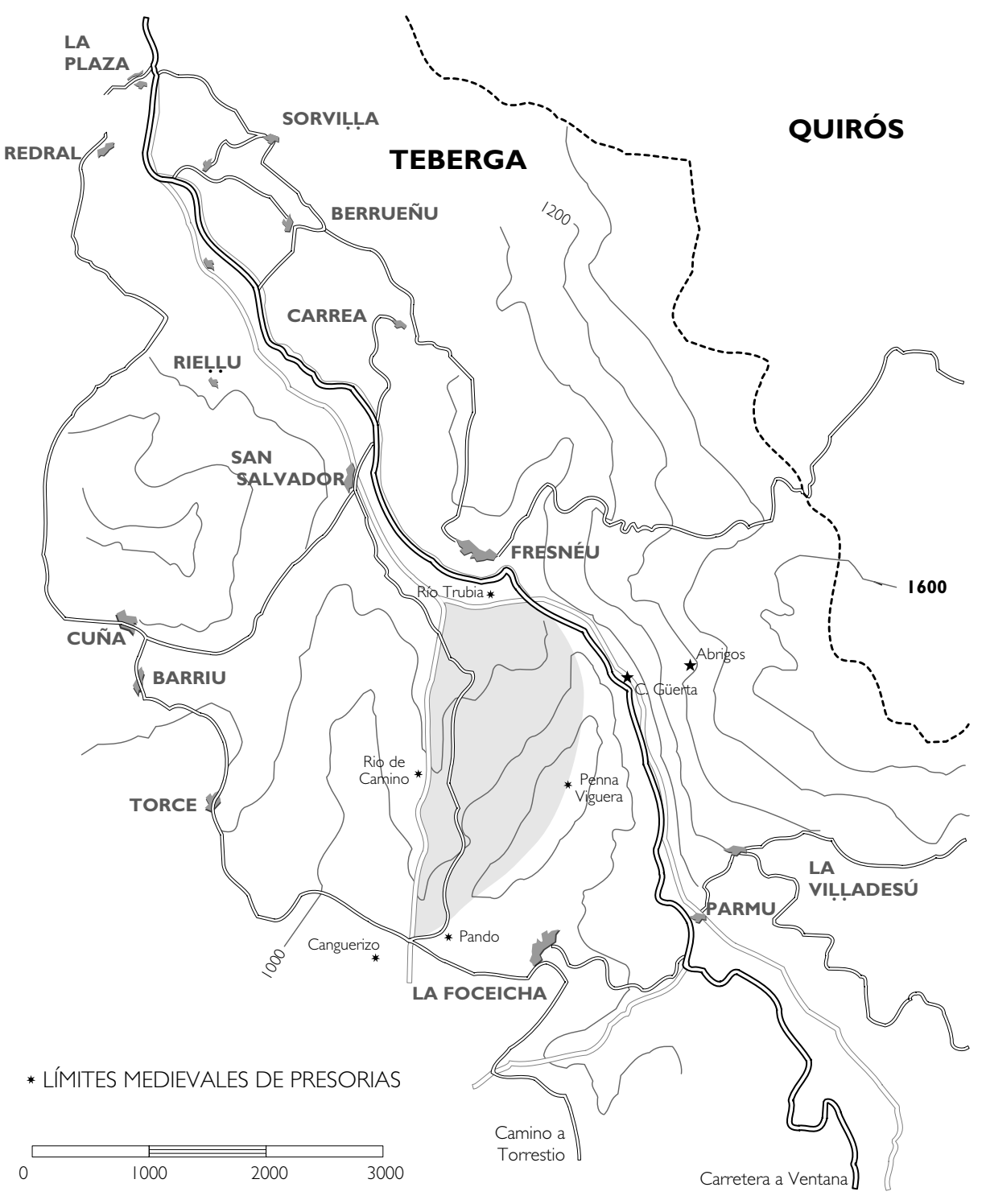




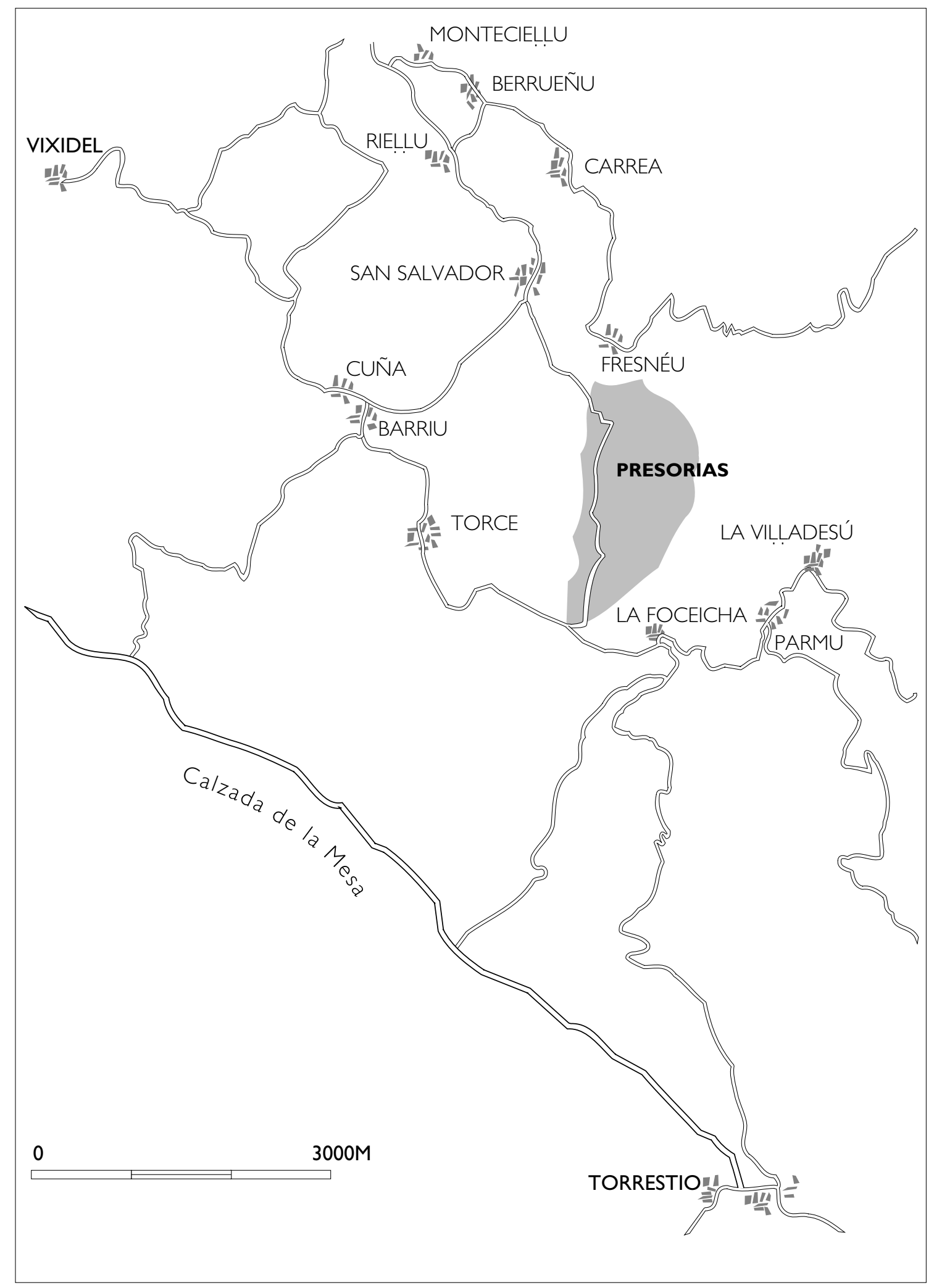

Fig. 3. 


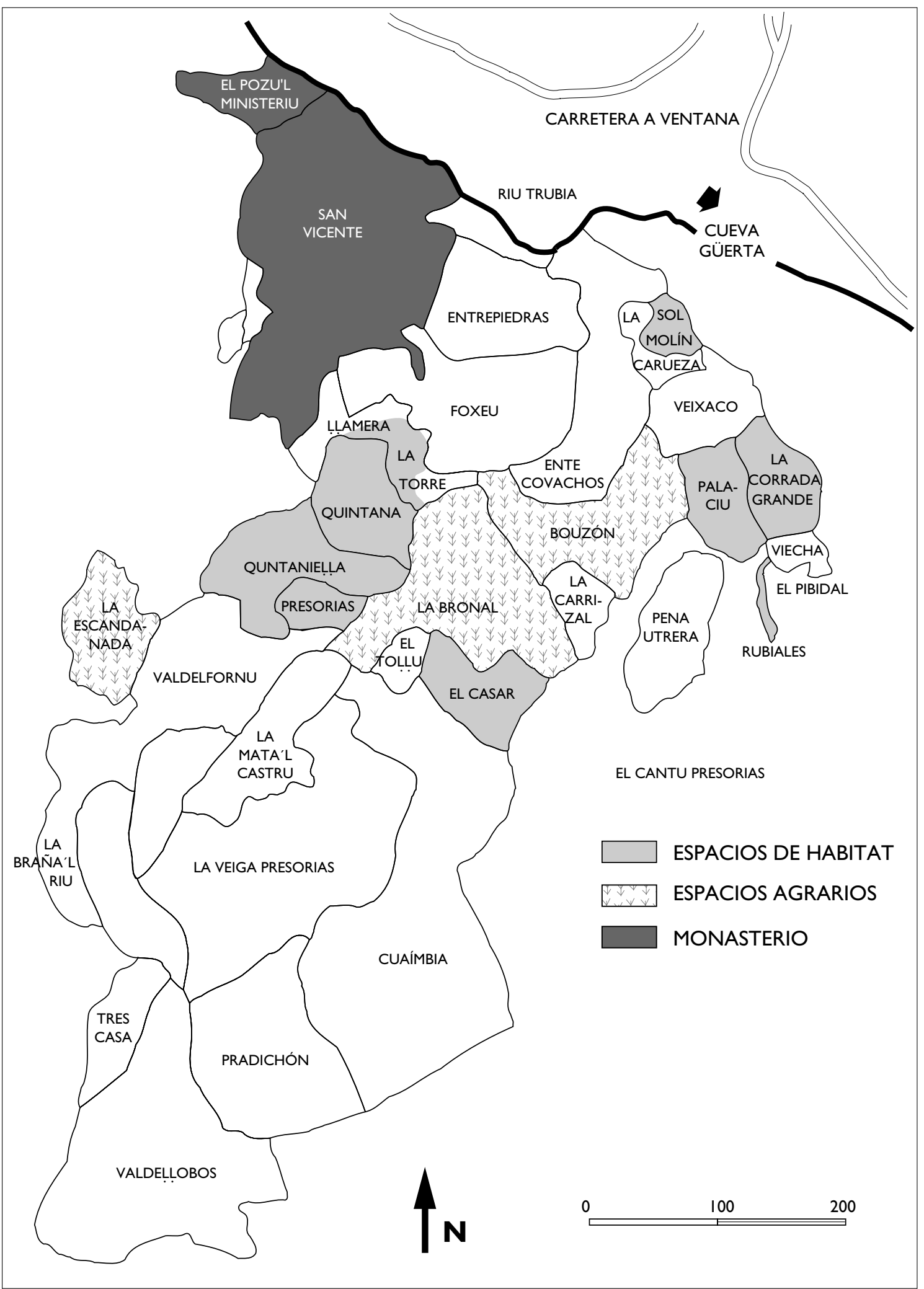

Fig. 4. Toponimia de Presorias 